\title{
The Concept of Emotionally-Colored Vocabulary and the Main Aspects of its Inter-Language Transmission
}

\author{
Abduvakhabova Dilnoza Nurmaxamatovna
}

\begin{abstract}
This article represents one of the most important and relevant problems of translation theory and practice today - the transfer of emotionally-colored vocabulary.
\end{abstract}

Keywords: emotion, perception, evaluative connotations, adequacy, equivalence, expressive.

\section{INTRODUCTION}

Translation as such can be considered as a complex form of communication. Emotionally-colored vocabulary, due to the fact that it shows a person's attitude to a particular subject, appraisal, expression, national thinking and perception of the world, is itself a rather complex system, which doubly complicates the process of its transmission to another language. For the transmission of emotional information in the language there is a large number of various lexical, syntactic and other means. They reflect the interaction of man and the world, manifested both in sensory perception and in the evaluative attitude of man to the world.

\subsection{Emotions in language}

The linguistic picture of the world is historically established in the everyday consciousness of a given linguistic group and reflected in the language a set of ideas about the world, a certain way of perception and structure of the world, conceptualization of reality. For the first time, the concept of a linguistic picture of the world was touched by Humboldt, noting that when it was formed, language was the expression of other sides of the human world that were parts of language $[2,47]$. The world of human emotions is one of the local pictures of the world. The significance of the world of emotions in studying and describing a picture of the world is due to the following. The picture of the world is not just a linguistic image of the real world, but, above all, a subjective image of objective reality created by man. The world is infinite, and man is limited and finite in his possibilities of comprehension. Any linguistic picture of the world inevitably contains traits of human subjectivity. It carries the traits of anthropomorphic, that is, the human mode of perception. This is not a mirror image of the world, but an interpretation that depends on a prism through which a person sees the world.

Revised Manuscript Received on July 22, 2019.

Abduvakhabova Dilnoza Nurmaxamatovna, Tashkent University of Information Technologies named after Muhammad al-Khwarizmi, Foreign languages department Yunusabad, Qashqar str Uzbekistan, Yunusabad, Amir Timur str. 108. Email id: abduvahabova0504@mail.ru.
It is worth noting that each nation has its own set of emotions and, in fact, many of them are similar to each other, representing general cultural phenomena, only their manifestations and language content are different. The success of negotiations sometimes depends on how far the parties are aware of national characteristics, traditions and manners towards each other. Mental competence is understood as knowledge that is used in the transmission or transferring of symbolic systems and their rules of behavior and principles of communication $[1,135]$. If we touch upon the linguistic picture of the world, then we can say that it is reflected in figurative associations in the process of perceiving a certain culture. According to L. Buyanova and Y. Nechay associations are verbal-artistic prisms that change impressions in different ways. These prisms underlie the so-called background emotions $[6,32]$. When it seems to us that a person is "tense", "annoyed", "sad", "full of energy", "sad" or "jovial", without saying a word to explain these states, we find the above-mentioned background emotions. At all times, people always experienced, experience and will experience the same feelings and emotions, be it joy or sorrow, anger or love, fun or sadness.

Emotions are an important part of our life. They relate to emotional processes and reflect the experiences that occur in various life situations.

As proved by scientists, emotions develop and change over time, the language of their transmission also changes. Scientists have always been interested in the emotions of a person and their reflection in linguistics. Many sciences, such as psychology, philosophy, medicine, literary criticism, cultural studies, linguistics, psycholinguistics, have studied human emotions and the mechanisms of their transmission. Thanks to this, we can speak about the emergence of a special literary language for the description of emotions and the language of expression of emotions. The statement that emotions are one of the forms of reflection, cognition, and evaluation of objective reality is recognized by representatives of various sciences, primarily by psychologists and philosophers. This initial position for all researchers has a general clarification: emotions are a special, peculiar form of cognition and reflection of reality, since in them a person acts as both an object and a subject of cognition, i.e. emotions associated with the needs of the person, underlying motives of his activities. 
According to the works of B.I. Dodonov, "emotions are nothing but the activity of evaluating information about the external and internal world entering the brain, which sensations and perceptions encode in the form of its subjective images" [7, 270]. "Emotions peculiar to man and manifested in purely individual, subjective forms, as well as socially determined assessments, being reflected by the human consciousness, become linguistic significance and constitute a certain part of the semantic content of the corresponding linguistic signs" [7, 4].

In linguistics, first of all, the problems of linguistic mechanisms of expression, designation and transmission of emotions are interesting. The mechanisms of linguistic expression of emotions of the speaker and linguistic designation, the interpretation of emotions as the objective essence of the speaker and hearer are fundamentally different. You can talk about the language of the description of emotions and language of expression of emotions. In order to differentiate vocabulary, at a certain stage the following terminological distinction appeared: vocabulary of emotions (nominative function, focused on objectivization of emotions) and emotional meanings (expressive and pragmatic functions, focused on the expression of the speaker's emotions and emotional evaluation). Special attention in linguistics of emotions is given to the study of the language category of emotiveness, which is understood as a functional-semantic category, which is used for external translation by native speakers (language personalities) of their emotional state and attitude to the world and having paradigmatic character at the lexical-semantic level $[4,41]$. In detailed study of the category of emotion usually raises the problem of emotive value. An emotive value is a value,that in a single structure of which there is a seme of emotiveness of one or another rank, i.e. this is a meaning in which emotive meanings are represented (expressed or marked) in some way. These meanings can be completely equal to the lexical meaning of the word (as in interjections), can be connotative (as in expressive), or can go into the logical-substantive part of the meaning (emotive-nominative). It is established that the emotive elements - linguistic or speech units - are the carriers of the emotive meaning: they call not so much a subject as an emotional relation to it.

\subsection{Determination of the emotional load of the word}

An important part of our research is the study of the word and its intrinsic coloring. It is a well-known fact that during translation, the translator often faces the problem of establishing the specificity and degree of emotional load of the word and text. As A.A. Leontev emphasizes.: "The problem of semantic perception should be viewed at different levels of speech flow organization: from the level of the word, through the level of a separate utterance to the text" [8, 34], i.e. it is the word as an element of the language system, or rather its emotional characteristics serve as the main means of imparting a certain color to the text.

It is important to remember that language is a means of expressing the personal, subjective attitude of the author to the subject of the utterance, while the problem of the language's emotionality, as N.M. Razinkina, the least developed in the field of lexicology, and in the field of stylistics [12.104]. There are many different terms and definitions for describing the emotional characteristics of a word, which often creates uncertainty and also complicates the study of this issue. For example, some authors use the term "emotional coloring of the word" [7, 92], while others use the term "expressive-stylistic coloring" [11.95]. One of the first classifications of emotional vocabulary, belonging to L. A. Piotrovskaya, includes three categories of functional-emotional vocabulary: 1) words with suffixes of diminution, magnifying, etc.; 2) portable uses of neutral words; 3) the words "concluding emotionality in their semantics" [13, 24].

The basic lexicographic criteria for defining a given vocabulary layer will be:

- vocabulary marks or special instructions in the text;

- the presence in the definition of the words of a subjective-emotional evaluation, calling the emotions and emotional states;

- the presence in the definition of words of an objective-emotional evaluation, denoting the properties and qualities that cause disapproval or approval;

- the presence in the definition of expression expression words, intensifier words.

It is worth noting that there have been attempts to create a linguistic theory of emotiveness. Despite the fact that the problem of emotivity today is increasingly attracting the attention of linguists and none of the modern fundamental research of the text can't do without pointing out the importance of studying its emotive aspect, emotivity remains a rather uncertain quality of the text. And again, to this day, linguists put very diverse meanings into this concept. V.I. Shakhovsky gave the following definition of emotiveness: "Emotive is the same as emotional, but about language, its units and their semantics. Emotivity is an inherent semantic property of language to express emotionality as a mental fact by the system of its means ..." $[11,156]$. L. A. Piotrovskaya defines emotivity as "the function of linguistic units associated with the expression of the speaker's emotional attitude towards objective reality" [13, 42]. However, the issue of emotiveness, at this stage, remains complex and not fully understood.

So how do you determine if a word is emotionally colored? As in the definition of emotionality of a word, so in relation to a question, one or another word is emotionally charged, quite different points of view were expressed. Next, we will try to highlight the main points of view on this issue. Most researchers on this issue adhere to the point of view put forward by N.M. Razinkina: "The field of emotional expressiveness covers the circle of feelings that is connected with the reciprocal relations of the speakers, the feelings socialized. Such socialization of feelings is explained by the fact that each person, being a representative of society, carries in itself and manifests the consciousness and mental structure characteristic of this society. the subjective qualities of a language are only in their origin, in terms of their psychological genesis, but in reality they exist as objective properties of the language

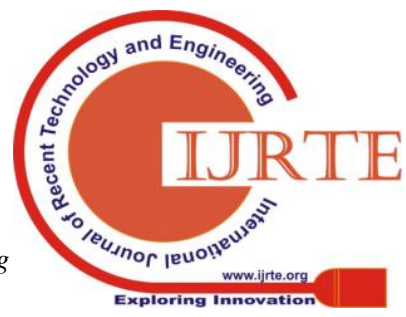


postglacial signs. We have the right to assert that in the language, not only in the psychology of speaking and writing, there is an objective emotion "[12,36].

\subsection{Translation of emotionally-colored vocabulary}

The main difficulties in translating emotionally-colored vocabulary are, in our opinion, the following problems: the preservation of emotional and evaluative connotations, the figurative component and lexical associativity.

The above questions allow us, from our point of view, to conclude that the translation of emotional and evaluative vocabulary requires the use of a special integrated translation technology.

Translation of stylistically colored vocabulary usually presents additional difficulties, since the search for an equivalent for the original lexeme is complicated by the presence in it, in addition to its denotative, connotative meaning. The equivalent chosen for translation should reflect the whole variety of functions of the lexical units of the original, including the development of expressive and emotional connotations in it. This explains the need for linguistic analysis of the work and its translations in a comparative aspect. The stylistic aspect of the translation is extremely important; it must be remembered that a translator could not and cannot get a high-quality literary translation without a competent stylistic transfer of the original. The overall quality of the translation will depend on how stylistically the original is transmitted. The mastery of the translator is extremely important in this light. Expression and emotional coloring of words in a work of art give greater expressiveness to the text, and their competent stylistic transmission also influences the final result of the translation. It is natural that for literary critics, linguists, and cultural scientists the main and most interesting problems are associated with literary translation. Literary translation is real art and creativity. Translators consider literary translation to be one of the most difficult.

The artistic style is perhaps the most complete of the functional styles described. However, it is unlikely from this it can be concluded that it is the most studied. This is explained by the fact that the artistic style is the most mobile, creatively developed of all styles. The artistic style does not know any obstacles in its path to a new, previously unknown. Moreover, novelty and unusual expression becomes a condition for successful communication within this functional style. The diverse topics covered in artistic texts (the life of a person, his inner world), the means that are used to reveal them, are also quite diverse. Moreover, every true artist of the word strives not to merge with his colleagues on the pen, but, on the contrary, to stand out, say something in a new way, draw attention to the readership. They say that it is necessary to study not the word, but the context. However, in a work of art not everything depends on the context. "A word has a lexical meaning recognized by native speakers and known to them even before its realization. Without contextual support, no contextual shades can arise. Secondly, in translation theory, a word is studied as a lexical unit implemented In other words, it is usually considered in its one meaning with all the shades accompanying it, depending on the context of any level and defined by the artistic whole. Thirdly, the word needs to be "rehabilitated" [5, 65].

The language of fiction, despite its heterogeneity and the author's individuality, still has a number of specific distinctive features. The language of fiction has a wide metaphor, a figurative language units of almost all levels, the use of synonyms of all types, polysemy, different style sheets of vocabulary.

One of the stages of literary translation is the perception of the text and the evaluation of the text's iconic properties. The perception of the text seems to be a rather complicated sensory-mental process based on various types and forms of analytical and synthesizing work of the sensory organs and the brain. The emotional reaction of the translator to the source text is determined both by the text's own properties and by the need to establish an analogy between complex informational and semiotic systems. T.Barkhudarov identifies the following stages in the perception of a literary text and in the overall translation assessment:

-sustainable emotional impression of understanding the original sign;

- emotional state in the process of finding matches;

-general emotional impression of the artistic text created by the translator himself.

"The emotional coloring of rational processes of mastering the source text and recreating it in the form of similarity in the language of translation creates a favorable basis for imaginary sign configurations in the interpreter's internal speech" [5, 156].

The transfer of the language of fiction is sometimes very difficult task T. Barkhudarov distinguishes two stages in the process of translating fiction: the first is connected with the interpretation of a text in a foreign language, the second with the reproduction of text in a native language. "The translator is obliged not only to understand the text and interpret it as an artistic whole, but also to perceive its emotional impact. The translator is usually required to know a foreign language, ability to use the richness of native speech and relative familiarity with what is being said in the translated work. A translator of fiction should be able to feel the emotions that the reading of the original is capable. In other words, the translator needs to be a sensitive receptor. The question of a translator as a receptor that can empathize with the author and feel the emotional mood of the work being translated does not have a scientific basis in translation theory, although an adequate translation, as is well known, largely depends not only on the rational perception of the work, on understanding the entire semantic content, but and from the accurate and fairly complete perception of the emotional-evaluative information contained in the original' $[5,24]$. In any case, the translator will contribute to the literary translation any elements with bstvennogo perception. "Having received the semantic and emotionally-expressive information contained in the phrase to be translated, the translator recreates this information in terms of the transfer material of language in order to maintain its full scope. He does not look, as it is sometimes accepted to think, of matching each word and phrase of the original phrase,

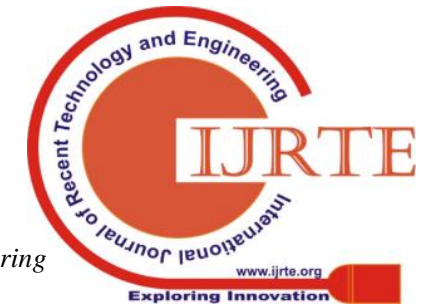


but "experiences" its meaning "[5, 28]. The translation technique does not recognize text upgrades based on the simple logic of equality of impressions: the perception of a work by the modern reader of the original must be similar to the modern reader of the translation. It is not a philologically authentic copy of the language of translation at the time when the original was written.

The search for an adequate equivalent and the competent transfer of the author's literary intention with the preservation of the time epoch of the original still remain an urgent issue. Despite the fact that quite a lot of works were devoted to the study of the language of fiction, and the basic principles to be followed by the translator are already known, the question of the quality of translation is still very acute, both in translating classical works and translating modern literature. Although the very concept of "quality translation" is very vague, many published translations of fiction can be given a very good assessment. "Improve" the translation can be infinite, in the end, still not having achieved one hundred percent transfer of the original. Accordingly, the dispute about exactly how, with what color, the author wanted to express and convey one or another phrase, can last a very long time. In many cases, having two or more translations of a work of art, it is possible, by comparative analysis, to determine a better and more accurate translation, but this often becomes an overwhelming task, since in many cases each translation of a certain work has its strengths and weaknesses. "The author of the original work is a master of one language, and the translator is a master of two languages. Provided that he is a good expert in the original language and at the same time perfectly fluent in his native language, for him the problem of linguistic correspondence practically does not exist, except for certain cases which can be met in the original work "[3, 178].

From the well-known works, mention should be made of the substantive article by Shakhovsky "The stages of the work of a translator", in which the author divided the whole process into three main stages:

- analysis of the original, consideration of its content, its semantics and style,

- searches in the language of translation and in the traditions of literature, existing in this language equivalent means of recreating the most important features of the original;

- Synthesis into a new artistic whole of the features identified in the original and transformed in accordance with the peculiarities of the literary language of the period and many other specific conditions [12,45]. A literary work often honors translation into another language. This can happen immediately after its creation, decades later or hundreds of years later. The temporal distance that separates the translation from the original affects the creative goals of the translator and the language features of the translated text. Based on the definition given by Komissarov V.N., a kind of activity is considered to be considered a literary translation. Its main task is to produce in the language of translation a piece of speech, which is characteristic of having some artistic and aesthetic impact on the language being translated. And it is precisely because of this definition that many critics have argued that literary translation is first of all subject to the artists of the word art, which is based on aesthetic criteria. Summing up the above, we can conclude that it is literary translation of texts that is both a linguistic fact and a literary fact. And only in literary translation, maximum deviations from the translated language are allowed, it is allowed for the sole purpose of ensuring the maximum artistic character of the translation $[9,120]$.

Close to modern approaches to the study of the problem of

\subsection{Emotionally expressive nature of partial correspondences during translation}

Speaking about the translation process itself, one cannot but touch upon the issue of translation comparisons. In literary translation, the translator, considering the lexical meaning of the word and its semantic nuances, determines its semantic load and its expressive-emotional power. Comparing the original text and its translations, it is possible to determine the information that must be transmitted or, on the contrary, omitted during translation. It will also allow to determine the methods used for compensation, as well as inconsistencies that inevitably occur during the translation of a work of art.

One of the first authors to speak about the problem of lexical correspondences was B.Kinzel. It was he who drew attention to the logical nature of lexical correspondences in the translation. He divided conformities into analogues, adequate replacements and equivalents. According to B.Kinzel equivalent is a constant equivalent correspondence, which for a certain time and place no longer depends on the context, analogue is the result of translation by analogy by choosing one of several possible synonyms, and an adequate substitute is used when "to accurately convey thought the translator must break away from the letter of the original, from vocabulary and phrasal correspondences and seek a solution to the problem, proceeding from the whole: from the content, ideological orientation and style of the original "[14, 78]. In the future, the above terms are relegated to second place due to low differentiation, as well as due to their partial synonymity. In his further works there will also be a clarification of terms: equivalents, variant and contextual correspondences, translational transformations of all kinds.

According to V.N. Komissarov translational correspondence is "a unit of the language of translation that is regularly used to translate a given unit of the language of the original" $[9,135]$.

According to the volume of information transmitted, correspondences are divided into complete (all extra-linguistic information is the same) and partial (the absence of a complete and accurate correlation between words). In our work it is important to consider the situation when the emotionally expressive (connotative, stylistic) component of the informative volume of the word of the original and the translation do not match. "For incomplete equivalents with stylistic discrepancies, semantic information is equivalent. That is why these equivalents are searched for in a synonymic series composed of so-called stylistic synonyms, by which they usually mean words having the same denotation, but differing in either expressive-emotional coloring or belonging to different functional styles of speech, i.e., essentially, two types of synonyms are combined stylistic and stylistic "[5, 67].

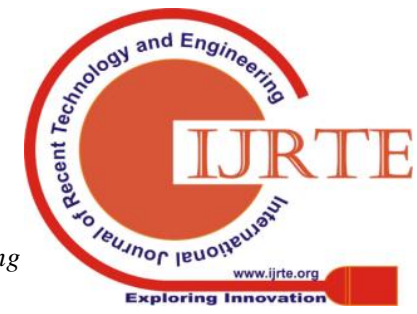


Often in fiction there are stylistically neutral words and phrases that, by virtue of the patterns of Russian stylistics, are replaced in translation by emotionally expressive words and phrases. This technique is called expressive concretization, that is, the replacement of a stylistically neutral word or expression with an emotionally colored one. In some cases, if there are no lexical units in the original that would require expressive replacement, depending on the context, there is a need for expressive additions. She also emphasizes that the use of expressive concretization in some cases is inevitably combined with compensation [13,140]. In addition, he points to cases in which expressive specification is used to emphasize and underline irony. At the same time, "other members of the sentence are involved in the orbit of this technique in the order of expressive coordination, regardless of what parts of speech they express" $[13,142]$. The translator should always remember about the style of the work, thereby placing a priority when choosing the appropriate lexical unit.

\subsection{Adequacy and equivalence in the translation of artistic text}

The question of the relationship between the original and translated texts in one way or another has been addressed throughout the history of translation and translation studies. Attempts to formulate this relationship in theoretical terms have led to the emergence of terms such as adequate and equivalent translations. An interesting fact is that these terms are etymologically related. They go back to the same Latin form "adeque", which translated means "equal, the same, the same." However, in the theory of translation, these two concepts acquired a different meaning. In addition, the same term was interpreted differently, with the result that certain difficulties arose in their understanding and use. First definition of "adequacy" was given by A.A. Smirnov in his article "Translation" in the Literary Encyclopedia: "We must recognize as adequate a translation in which all the author's intentions (both thought out by him and unconscious ones) are conveyed in the sense of a certain ideological and emotional artistic impact on the reader as far as possible [by exact equivalents or satisfactory substitutes (substitutions)] of all the imagery, color, rhythm, etc. used by the author; the latter should be considered, however, not as an end in itself, but only as a means for to achieve a general effect. Without a doubt, one has to sacrifice something, choosing less essential elements of the text. To this end, the translator must, before starting work, get a clear idea of the ideology, style and literary texture of the work being translated, moreover - of all the work of its author, as well as, if possible, other representatives of the same literary school and even other, adjacent to it, even antagonistic directions ".

V.N. Komisarov gave the following definition of adequacy and equivalence: "Adequate translation is translation, which provides the pragmatic tasks of the translation act at the highest possible level of equivalence to achieve this goal, preventing violations of the norms or uzus PL, observing the genre-stylistic requirements for texts of this type and corresponding -Accepted conventional rate of translation.In loose use, "adequate translation" is a "good" translation that justifies the expectations and hopes of the communi Ants or persons carrying out the translation quality assessment. The equivalent transfer is called translation, which reproduces the contents of the original foreign language in one of the equivalence of levels. The content of the original refers to all the information transmitted, including both subject-logical (denotative) and connotative meaning of the language units that make up the translated text, as well as the pragmatic potential of the text. By definition, any adequate translation should be equivalent (at one or another level of equivalence), but not any equivalent translation is recognized as adequate, but only one that meets, in addition to the equivalence norm, other regulatory requirements mentioned above "[9, 133].

It should be emphasized that the equivalence of the original and the translation is, above all, a common understanding of the information contained in the text, including that which affects not only the mind, but also the feelings of the recipient and which is not only explicitly expressed in the text, but also implicitly related to subtext. The importance of the category of equivalence notes R. Jacobson. "Equivalence in the existence of differences," he writes, "is the cardinal problem of language and the central problem of linguistics. Like any recipient of a verbal message, the linguist is his interpreter. The science of language cannot interpret any linguistic phenomenon without translating its signs into other signs system or signs of another system. Any comparison of two languages implies consideration of their mutual translatability ".

R.Bavdinev, in turn, equates the concepts of adequacy and equivalence: "The concepts of adequacy, identity, full value and even similarity remain in the same semantic field as the term" equivalence "and sometimes duplicate each other. Under the equivalence, in translation theory should be understood conservation relative equality of meaningful, semantic, semantic, stylistic and functionally communicative information contained in the original and the translation. It should be emphasized that the equivalence ginal and translation is, first of all, a common understanding of the information contained in the text, including that which affects not only the mind, but also the feelings of the recipient and which is not only explicitly expressed in the text, but also implicitly related to the subtext "[3, 179].

In literary translation there are special laws of equivalence and adequacy to the original. Translation can, as already mentioned, only infinitely converge with the original. Because a literary translation has its own creator, its own linguistic material, and its own life in a linguistic, literary and social environment that is different from the environment of the original. Literary translation is generated by the original, it depends on it, but at the same time it possesses relative autonomy, as it becomes a fact of a translating language. Therefore, the development of the same work in different cultures has its own specifics, its own differences, its own history. Thus, not only the original and the translation differ in the character of the comprehension, social significance and reputation, but also the multilingual translations of the same literary source. But there are other reasons for the relative equivalence of literary translation to the original. They are caused by the peculiar perception of the original by the translator, the diversity of languages, and differences in the socio-cultural environment.

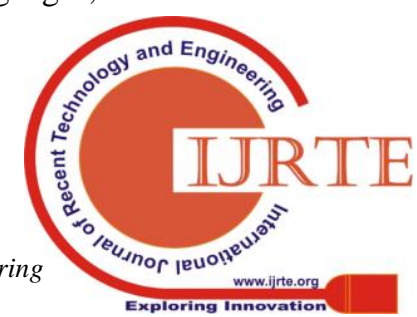


The individuality of the translator will also appear, determined by his artistic perception, talent, and originality of the selection of language means. These traits due to the individuality of the translator have nothing to do with the author's style of the original, they are not directly related to the text of the original. Their paradox is that they are undesirable, but inevitable. These are elements of the translation style. Problems of translator's style are not yet theoretically understood in translation studies, although there are already some statements on this subject.

From the above, it becomes clear that, despite the desire of the translator to recreate the content, emotionally expressive and aesthetic value of the original as fully as possible, and to achieve an equal impact on the reader, the translator, with the original, one can only rely on the relative equivalence of the literary translation to the original text. The equivalence of the impact of the original and the translation on the reader will be relative to an even greater extent.

For a more complete picture, it seems appropriate to also address in this chapter the problem of the variability of the notion of equivalence, on which the main emphasis is laid in the works of many authors. So, for example, L. Latishev believes that the concept of "equivalence" acquires real meaning in the case when its type or type is specified. The type of equivalence is clarified by specifying the specific properties of the original, which should be preserved during the translation process. L. Latishev identified the following types of equivalence: 1) denotative (associated with the preservation of the subject content of the text);2) connotative (here we are talking about the transfer of connotations of the text by choosing synonymous language means); 3) textual and regulatory, (this kind of equivalence is focused on the genre features of the text, on speech and language norms); 4) pragmatic, (with a specific installation on the recipient); 5) formal (associated with the transfer of artistic and aesthetic, puns, individualizing, as well as other formal features of the original) $[10,160]$.

Unlike L. Latishev V.N. Komissarov distinguish the following levels of equivalence, depending on the method of representation in the translation of certain parts of the original: - communication goals

- identification of the situation

- method of describing situations

- values of syntactic structures

- word signs [9,201].

\section{RESULTS}

This research get results on translation of emotionally-colored vocabulary involved many linguists and translators. On this case, received better ways of emotional coloring, the translator needs to accurately convey all the colors of the original while preserving the originality of the era, without lowering the information specified in the original text as the whole.

\section{CONCLUSION}

The problem of translation of emotionally-colored vocabulary involved many linguists and translators. Each of them offered his recommendations on the best ways to translate them, but they all agree that, in addition to the need for deep knowledge of the language of emotions and vocabulary with emotional coloring, the translator needs to accurately convey all the colors of the original while preserving the originality of the era, without lowering the information specified in the original text. Only in this case will it be possible to achieve the greatest equivalence in the transfer of the emotional charge of one or another original unit in the translated text.

The correct transfer plays a big role in the translation. Possessing concrete means of transmitting emotionally expressive information, the translator is given the opportunity to assess the degree of emotionality of the text and, accordingly, to give its own assessment of the translation with the help of a comparative analysis. Transformations are necessary to achieve adequate translation. The main transformations in the translation of emotionally-colored vocabulary in a work of art are: permutations, substitutions, omissions, additions.

This research get results on translation of emotionally-colored vocabulary involved many linguists and translators. On this case, each of them offered his recommendations on the best ways to translate them, but they all agree that, in addition to the need for deep knowledge of the language of emotions and vocabulary with emotional coloring, the translator needs to accurately convey all the colors of the original while preserving the originality of the era, without lowering the information specified in the original text

\section{ACKNOWLEDGMENT}

In developing and writing this article, I received inspirations from different people and few sources. First of all, I would want to thank my lecturer (DcS Nargiza Tuhtaxodjayeva), who has been with me from the day I began my research. He had helped me design and go through this article when I asked her questions about translation theory and comparative linguistics and was ready to help. I would also wish to thank my department (Foreign Languages), that helped me with enough resources during my study. Development of linguistics inspired me on my views about languages, how I learn these languages and as well as the research. And lastly, I acknowledge my colleagues who played a role in the discussions and research in the libraries to make this article happen.

\section{REFERENCES}

1. Abduvahobova D.N. Intercultural communication and problems of teaching English to students-nonlinguists. Foreign languages in Uzbekistan-scientific methodological electronic journal, $\mathrm{N}$ 1(20)/2018.135-139p.

2. Babenko L. G. Linguistic analysis of a work of art. - Ekaterinburg: Ural publishing house, University, 2000. - 534p.

3. 3.Bavdinov P.P. Cultural connotation and parish units / P.P. Bavdinov. // Bulletin of the KazNU. A series of philological. - 2005 №8. - with. 177-180.

4. Bagdasarova N.A. Lexical Expression of Emotions in the Context of Different Cultures: Thesis Abstract, Moscow, 2004. - 22 p.

5. Barkhudarov, L.S. Language and translation. - M .: International Relations, 1975.-240 p. 
6. 6.Buyanova L.Yu., Nechay Yu.P. Emotiveness and emotiogenicity of language: mechanisms of explication and conceptualization: monograph. - Krasnodar: Kuban State. University, 2006.-277 p.

7. 7.Dodonov B.I. Emotion as a value. - M .: Politizdat, 1978 - 272 p. Dridze TM,

8. Leontiev A.A. The semantic perception of speech messages (in terms of mass communication) - Moscow: Nauka, 1976. - 263 p.

9. Komissarov, V.N. Theory of Translation (linguistic aspects). - M .: Higher School, 1990. - 253 p.

10. 10.Latyshev L.K. Translation rate (equivalence and ways to achieve it) Text. / L.K. Latyshev. - M .: International relations, 1981.-284 p.

11. Shakhovsky, V.I., Categorization of Emotions in the Lexical-Semantic System of the Language, Voronezh: Voronezh Publishing House. Un 1987, 192 p.

12. 12.Razinkina N.M. The style of English scientific speech. - M . Science, 1972. - $168 \mathrm{p}$.

13. 13.Piotrovskaya L.A. Emotive statements as an object of linguistic research (on the material of Russian and Czech languages): Monograph. - SPb .: Publishing house of S.-Petersburg. University, 1994. - $146 \mathrm{p}$

14. Kinzel A.B. Psycholinguistic study of the emotional-semantic dominant as a text-forming factor. - Barnaul: Publishing house Alt. University, 2000. - $152 \mathrm{p}$.

15. A.A.Smirnov"Translation" Literary Encyclopedia, 1996, 155-159p. 